Brazilian Journal
of Chemical
Engineering

\title{
NUTRIENT BALANCE AND METABOLIC ANALYSIS IN A Kluyveromyces marxianus FERMENTATION WITH LACTOSE-ADDED WHEY
}

\author{
J. Parrondo, L. A. García, and M. Díaz \\ Department of Chemical Engineering and Environmental Technology, Faculty of Chemistry, \\ University of Oviedo, C/ Julian Claveria s/n. 33071 Oviedo, Spain. \\ E-mail:mariodiaz@uniovi.es
}

(Submitted: February 21, 2007 ; Revised: November 14, 2007 ; Accepted: December 10, 2007)

\begin{abstract}
Addition of lactose on whey to produce an alcoholic product by fermentation is optimized in order to maximise final ethanol concentrations and lactose consumption. The effect of the supplementation of the broth with yeast extract, ammonium sulphate, oxygen, protein, peptides and the vitamins nicotinic acid, biotin, pantothenic acid and inositol on aerobic cell growth was also studied. The Crabtree-negative yeast Kluyveromyces marxianus is employed in this study, so oxygen should enhance cell growth and reduce ethanol production. Addition of yeast extract, a source of vitamins, shifts metabolism towards fermentation. The same effect is observed when nicotinic acid and biotin are added to the medium. Individual and mixed effects of the four assayed vitamins are studied, showing that combinations of two or more vitamins diminished cell growth and lactose consumption and increased ethanol production.

Keywords: Whey; Lactose; Kluyveromyces marxianus; Vitamins; Nitrogen sources.
\end{abstract}

\section{INTRODUCTION}

During the nineteen seventies and eighties there was considerable interest among various governments and scientific communities in producing ethanol from renewable resources such as whey (Guimaraes et al., 1992; Vienne and von Stockar, 1985). The main objective of the studies conducted was to produce ethanol for use as a fuel or fuel additive. This interest subsequently declined as oil prices fell, but it is now rekindling, not only because oil prices are again high but also because of the desirability of renewable resources and the general aim of sustainability. Another strategy is to use whey to produce alcoholic products (Parrondo et al., 2000). This choice is interesting because prices are much higher than when it is employed as fuel. This application of whey is studied in the present paper.
The yeast employed in this study belongs to the species $K$. marxianus. Formerly K. fragilis, which is yeast capable of consuming lactose. Fermentation of whey after lactose hydrolysis with $\beta$-galactosidase, with a strain of Saccharomyces cerevisiae has also been reported (Hahn-Hagerdal, 1980). In this case, the hydrolysis step makes the process more complicated and expensive, due to the high amounts of enzymes needed and their high costs. Another possibility is to employ a recombinant strain of Saccharomyces cerevisiae (Dominges et al., 2001), which gives better yields and higher ethanol concentrations than those obtained with yeast of the genus Kluyveromyces, although its use might be restricted by food and health legislation.

Several studies have been published concerning the influence of the nutritional composition of culture media on the behaviour of $K$. marxianus in batch and continuous cultures (Antier et al., 1990;

*To whom correspondence should be addressed 
Harju et al., 1976; Kallel et al., 1991; Rodney and Greenfield, 1984). In most of those studies, whey is supplemented with several additives to enhance fermentation rates. In several of them (Kallel-Mhiri and Miclo, 1995; Kallel-Mhiri et al., 1994; Vienne and von Stockar, 1985) whey or whey permeate is supplemented with yeast extract in order to increase ethanol productivity and ethanol/ lactose yield.

Several authors describe the use of whey supplemented with more than one nutrient (Belem and Lee, 1999; Castrillo and Ugalde, 1993; KallelMhiri and Miclo, 1995; Kallel-Mhiri et al., 1994) in order to overcome nutritional limitations. Kallel et al. (1991) study nutritional limitations in the continuous growth of $K$. marxianus on whey permeate. In these studies, $\mathrm{Fe}^{3+}$ and nicotinic acid are found to be the main limiting growth factors of ultra filtered whey. Limitations in nitrogen source, phosphorus, and vitamins are found in other studies (Harju et al., 1976).

Differences between published results are due to the different types of whey utilized, different strains of yeast employed, and also to differing cultivation conditions. While some use batch cultures (Harju et al., 1976), others use continuous cultures (Castrillo and Ugalde, 1993; Kallel et al., 1991; Vienne and von Stockar, 1985) or fed-batch cultures (Belem and Lee, 1999). Because of these differences, nutritional limitations must be tested for the specific conditions and materials employed in our study.

The aim of the present study is to perform metabolic studies to better understand the effect of certain substrates in the growth and ethanol production of Kluyveromyces marxianus These studies are designed to improve both biomass and ethanol yield during the stages of inoculum development, under aerobic conditions and during the process of ethanol production under anaerobic conditions to finally enhance the overall fermentation performance.

\section{MATERIALS AND METHODS}

\section{Culture Medium}

The base medium employed in this study was sweet whey supplemented with food grade lactose. The medium consisted of $78 \mathrm{~g}$ of powdered whey, $100 \mathrm{~g}$ of lactose, and $1000 \mathrm{~g}$ of distilled water. Whey and lactose were provided by the dairy Reny Picot S.A. (Anleo-Navia, Asturias, Spain). Whey was supplemented with lactose in order to increase its initial concentration and subsequently the level of ethanol produced via alcoholic fermentation by yeast. This whey was also supplemented with $\mathrm{FeCl}_{3}$ (24 mg/l) since in previous studies (Kallel et al, 1991) a deficit in $\mathrm{Fe}^{3+}$ was detected.

The medium had a final density of $1055 \mathrm{~kg} / \mathrm{m}^{3}$, a lactose concentration of $139 \mathrm{~kg} / \mathrm{m}^{3}$, and a protein concentration of $9 \mathrm{~kg} / \mathrm{m}^{3}$. It was pasteurised before fermentation by heating it to $65^{\circ} \mathrm{C}$ for 30 minutes. The whey had the following composition on a dry basis: $0.8 \% \mathrm{w} / \mathrm{w}$ fat, $11 \% \mathrm{w} / \mathrm{w}$ total nitrogen (Kendahl method), $77 \% \mathrm{w} / \mathrm{w}$ lactose and $11 \% \mathrm{w} / \mathrm{w}$ ash.

\section{Yeast and Culture Conditions}

The lactose fermenting yeast employed in this study was $K$. marxianus (Spanish Type Culture Collection, CECT 1123). Cultures of this yeast were kept for less than three months on agar slopes prepared with the following media (TYED + agar); triptone: $2 \mathrm{~g}$, yeast extract: $1 \mathrm{~g}$, D-glucose: $2 \mathrm{~g}$, agar: $2 \mathrm{~g}$, and water: $100 \mathrm{~mL}$ [17]. When new slopes needed to be prepared, cells were grown in a liquid medium for 24-48 $\mathrm{h}$ from a culture stored in glycerol at $-20^{\circ} \mathrm{C}$.

Inoculum was prepared in two steps. Firstly, a single colony obtained from a Petri dish was used to inoculate a small amount of TYED medium $(10 \mathrm{~mL}$ of TYED in a $50 \mathrm{~mL}$ flask) and propagated for around 24 hours in a New Brunswick Incubator, operating at $30^{\circ} \mathrm{C}$ and 200 r.p.m. This culture was transferred at the end of exponential growth phase to $100 \mathrm{~mL}$ (500 mL flask) of fresh medium with the following composition; triptone: $2 \mathrm{~g}$, yeast extract: $1 \mathrm{~g}$, lactose: $15 \mathrm{~g}$, and water: $100 \mathrm{ml}$, and propagated for a further day under the same conditions. This culture was employed as inoculum in a ratio of 10 volumes per 100 volumes of fermentation medium. The inoculums were transferred at the end of the exponential growth phase.

In the experiments carried out for this study two different bioreactors were employed. Erlenmeyer flasks closed with cotton bungs were employed for cell culturing in batches. Experiments were carried out using $250 \mathrm{~mL}$ flasks with $100 \mathrm{~mL}$ cultivation medium. Pure oxygen was bubbled through the broth, with 0.3 or $0.6 \mathrm{~L}$ oxygen per flask per minute, depending on the case. Experiments were carried out at $30^{\circ} \mathrm{C}$ and 200 r.p.m. in the incubator mentioned above.

When more controlled culture conditions were needed, a 5-litre capacity commercial bioreactor (BIOFLO III from New Brunswick Scientific Co., Inc) was used, with agitation, temperature, dissolved 
oxygen, $\mathrm{pH}$ and foam controllers and the corresponding peristaltic pumps, allowing batch, fedbatch or continuous operation. The $\mathrm{pH}$ was left to vary freely from the initial value. Foam was removed by automatic addition of antifoam (SIGMA 289).

\section{Analytical Methods}

Cell growth was determined by measuring dry weight. $1 \mathrm{~mL}$ samples were centrifuged in preweighted Eppendorf tubes, washed with distilled water and placed in an oven at $110^{\circ} \mathrm{C}$ for 48 hours until constant weight was reached.

Lactose was determined using the dinitrosalicylic acid method (Miller, 1959). Briefly, $1 \mathrm{~mL}$ of DNS reactive ( $8 \mathrm{~g} \mathrm{NaOH}, 150$ sodium and potassium tartrate, $5 \mathrm{~g}$ dinitrosalicylic acid, and $500 \mathrm{~mL}$ distilled water) was added to a $1 \mathrm{~mL}$ sample, diluted to bring the lactose concentration down to less than 2 $\mathrm{g} / \mathrm{l}$. The tubes with the reaction mixture were heated in a boiling bath for 5 minutes and then cooled in an ice bath and diluted with $10 \mathrm{~mL}$ of distilled water. Absorbance was measured at $540 \mathrm{~nm}$ (Peña et al., 2000). A blank sample was prepared with the same procedure using distilled water instead of the problem sample. Sample concentration was calculated based on a calibration curve determined by using a known solution of lactose.

Ethanol was analysed by gas chromatography using a Shimadzu GC 14B chromatograph with flame ionisation detector. A SUPELCOWAX 10 (SUPELCO) capillary column $60 \mathrm{~m}$ long, with 0.25 $\mathrm{mm}$ inside diameter and $0.25 \mu \mathrm{m}$ film thickness was used (Parrondo et al., 2000). The oven temperature was set initially at $40^{\circ} \mathrm{C}$, held for 10 minutes, ramped to $80^{\circ} \mathrm{C}$ at a rate of $4^{\circ} \mathrm{C} / \mathrm{min}$, held there for 10 minutes and then ramped to $200^{\circ} \mathrm{C}$ at $35^{\circ} \mathrm{C} / \mathrm{min}$, with a final hold at $200^{\circ} \mathrm{C}$ for 15 minutes. Split injections of $1 \mu \mathrm{L}$ were applied at an injection port temperature of $200^{\circ} \mathrm{C}$. The temperature of the flame ionisation detector was $230^{\circ} \mathrm{C}$. The split and purge flows were fixed at 20 and $4 \mathrm{ml} / \mathrm{min}$. Helium inlet pressure was fixed at $150 \mathrm{kPa}$ (around $1 \mathrm{ml} / \mathrm{min}$ ). Detector pressures were as follows; hydrogen: 60 $\mathrm{kPa}$, air: $60 \mathrm{kPa}$, and make-up helium $80 \mathrm{kPa}$. Detector sensibility was set at $10^{1}$. Ethanol was quantified by external standards using 1-propanol as the internal standard. Each sample was injected three times to assure reproducibility (variation coefficient less than 6\%)

Phosphate was analysed by the phosphomolybdic complex method. Protein, peptides and amino acids were analysed by the Lowry method. The peptides were analysed after precipitation of protein in the samples with trichloroacetic acid $10 \% \mathrm{w} / \mathrm{w}$.

\section{Kinetic Model}

An unstructured model was employed to simulate yeast growth, lactose consumption and ethanol production. Cell growth was assumed to be proportional to cell concentration and the final equation contains an inhibition factor proportional to the square of cell concentration. Yeast cell growth is described by a Riccati equation of the type:

$\mathrm{r}_{\mathrm{X}}=\frac{\mathrm{dX}}{\mathrm{dt}}=\mathrm{k}_{\mathrm{x}} \mathrm{X}\left(1-\mathrm{k}_{\mathrm{xi}} \mathrm{X}\right) ; \quad \mathrm{X}(\mathrm{t}=0)=\mathrm{X}_{0}$

where $r_{X}$ is the yeast cell growth, $X$ the yeast cell concentration expressed as cell dry weight, and $k_{x}$ and $k_{x i}$ the two parameters of the model. This equation can be integrated by separation of variables to give the logistic curve equation:

$X(t)=\frac{X_{0} \exp \left(k_{x} t\right)}{1-k_{x i} X_{0}\left(1-\exp \left(k_{x} t\right)\right)}$

where $X_{0}$ is the yeast dry weight at the beginning of the fermentation.

The rate of lactose consumption is due to yeast cell growth during the exponential phase of growth and also to cellular maintenance when yeast growth is stopped. The following equation was used to model the rate of lactose consumption:

$-r_{S}=-\frac{d S}{d t}=\frac{1}{Y_{X / S}} \frac{d X}{d t}+m X$

where $S$ is the lactose concentration in the broth, $Y_{X / S}$ the biomass/ lactose yield, and $m$ the cellular maintenance coefficient.

Ethanol is the end product of lactose metabolism and hence its production is directly related to lactose consumption. Ethanol production can be modelled using the following equation:

$\mathrm{r}_{\mathrm{P}}=\frac{\mathrm{dP}}{\mathrm{dt}}=\mathrm{Y}_{\mathrm{P} / \mathrm{S}} \frac{\mathrm{dS}}{\mathrm{dt}}$

where $P$ is the ethanol concentration, and $Y_{P / S}$ the ethanol/ lactose yield. 


\section{RESULTS AND DISCUSSION}

\section{Effect of Lactose Addition on Alcoholic Fermentation of Whey}

The objective was to increase the concentration of ethanol in the alcoholic end product. To achieve this, initial concentration of lactose in whey needed to be optimized. Accordingly, four initial lactose concentrations in the whey based medium (44, 85, 127 and $166 \mathrm{~g} / \mathrm{l}$ ) were assayed. Fermentation broth was prepared as described in Material and Methods Culture Medium. Experiments were carried out by incubating $100 \mathrm{ml}$ of the different media in $250 \mathrm{ml}$ Erlenmeyer flasks in an orbital incubator, as described in Material and Methods - Yeast and Culture Conditions. The effect of lactose concentration on yeast cell growth is shown in Figure 1.

When initial lactose concentration was increased from 44 to $127 \mathrm{~g} / \mathrm{L}$, the final concentration of yeast (dry weight) rose by $20 \%$. With a higher initial lactose concentration (166 g/L) final biomass concentration decreases. Yeast cell growth was modelled using the logistic model (equation 1), which describes the exponential growth and the stationary phase. Model parameters ( $k_{x}$ and $k_{x i}$ ), confidence intervals and determination coefficients resulting from the fit are shown in Table 1 . The determination coefficients (percentage of variance explained by regression) were over 0.99 , so the fit of the data to the model was very good. Parameter $k_{x}$ decreased when lactose concentration increased, probably due to an osmotic inhibition of cell growth. On the other hand, final biomass concentration $\left(1 / k_{x i}\right)$ increased when sugar concentration increased, except when it reached $166 \mathrm{~g} / \mathrm{L}$, which may be related to an inhibition effect appearing at this high sugar concentration affecting the physiological behaviour of the yeast. In any event, specific growth rates $\left(k_{x}\right)$ deviated less than $15 \%$ from the ones obtained by other authors (Walker and O’Neill, 1990).

The changes over time in the ethanol concentration in the fermentation broth were also determined. Results are shown in Figure 2. Curves of ethanol production display two zones: the first showing high ethanol productivity during exponential growth of the yeast and the second with slow or even zero ethanol productivity when the initial concentration of lactose was $44 \mathrm{~g} / \mathrm{L}$. A final ethanol concentration of $40 \mathrm{~g} / \mathrm{L}$ was reached with an initial lactose concentration of $85 \mathrm{~g} / \mathrm{L}$. When lactose was increased from 85 to $127 \mathrm{~g} / \mathrm{L}$, ethanol concentration changed from 40 to $56 \mathrm{~g} / \mathrm{L}$. Curves for ethanol production in fermentations carried out with 127 and 166 g lactose/L were very similar. With an initial concentration of lactose higher than $166 \mathrm{~g} / \mathrm{L}$, slower yeast cell growth is expected and hence lower ethanol productivity. This is because the specific grow rate decreases when increasing the concentration. If the increase in the concentration until $166 \mathrm{~g} / \mathrm{L}$ decreases the growth rate of the yeast, it is expected that an additional increase would result in lower growth rates.

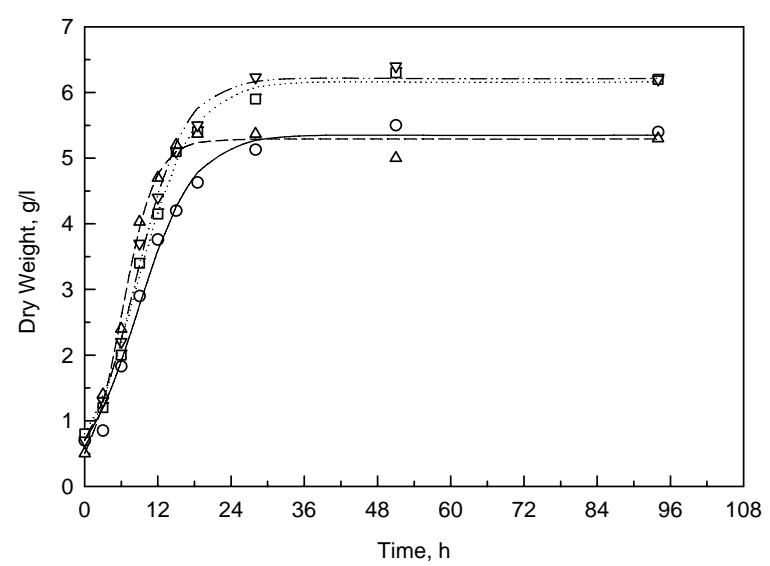

Figure 1: Yeast cell growth during fermentation of K. marxianus in whey supplemented with lactose: $(\triangle)$ 44, $(\nabla)$ 85, ( $\square)$ 127, (०) $166 \mathrm{~g} / \mathrm{L}$. Model is shown as lines.

Table 1: Model parameters, $\mathbf{9 5 \%}$ confidence levels, and determination coefficients calculated for data fit to the model proposed, for different initial lactose concentrations.

\begin{tabular}{|l|r|r|r|r|}
\hline Lactose initial concentration, g/l & $\mathbf{4 4}$ & \multicolumn{1}{|c|}{$\mathbf{8 5}$} & $\mathbf{1 2 7}$ & $\mathbf{1 6 6}$ \\
\hline$k_{X}, \mathrm{~h}^{-1}$ & 0.37 & 0.25 & 0.22 & 0.22 \\
$95 \% \mathrm{CI}, \mathrm{h}^{-1}$ & $0.33-0.40$ & $0.23-0.27$ & $0.20-0.24$ & $0.19-0.24$ \\
$k_{X i}, \mathrm{l} / \mathrm{g}$ & 0.19 & 0.16 & 0.16 & 0.19 \\
$95 \% \mathrm{CI}, \mathrm{l} / \mathrm{g}$ & $0.18-0.20$ & $0.15-0.17$ & $0.15-0.17$ & $0.18-0.20$ \\
Determination coefficient $\left(\mathrm{R}^{2}\right)$ & 0.994 & 0.994 & 0.995 & 0.992 \\
\hline
\end{tabular}




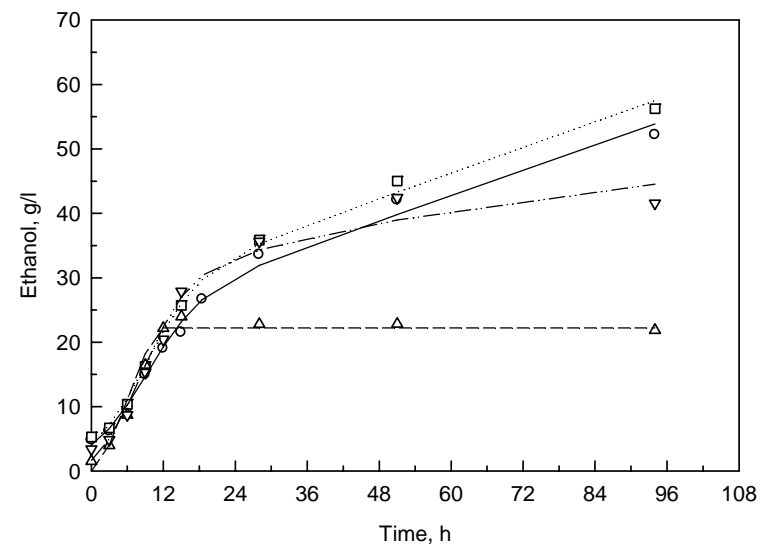

Figure 2: Ethanol production during K. marxianus fermentation of whey supplemented with lactose: $(\triangle)$ 44, $(\nabla)$ 85, ( $\square$ ) 127, (O) $166 \mathrm{~g} / \mathrm{L}$. Model is shown as lines.

Figure 3 shows the changes over time in lactose concentration for the different concentrations assayed. As can be seen, in all cases there is an initial period of rapid consumption up to 12-18 hours, followed by a slower consumption period. Lactose consumption is also modelled using the equations (1)-(4). The parameters obtained are shown in Table 2. The biomass/lactose yield remains almost constant; a mean value of $0.09 \mathrm{~g}$ of cell dry weight per $\mathrm{g}$ lactose is calculated. The results are in agreement with other published data, the deviation being less than 15\% (Dale et al., 1994; Ferrari et al., 1994; Vienne and von Stockar, 1985; Walker and O’Neil, 1990).
Ethanol/lactose yield and the coefficients determined from the fit of the data to the model are also shown in Table 2. A slight decrease in the ethanol/lactose yield is observed when the lactose concentration was increased from $44 \mathrm{~g} / \mathrm{L}$ to $166 \mathrm{~g} / \mathrm{L}$ (Table 2). The efficiency of alcoholic process, i.e., the actual yield divided by the maximum attainable yield, decreases from $94 \%$ to $83 \%$ (Table 2) when lactose increases from 44-85 to 127-166 g/L. These efficiency levels are calculated assuming a theoretical ethanol production, by means of alcoholic fermentation, of $0.54 \mathrm{~g}$ of ethanol per $\mathrm{g}$ of lactose consumed by yeast.

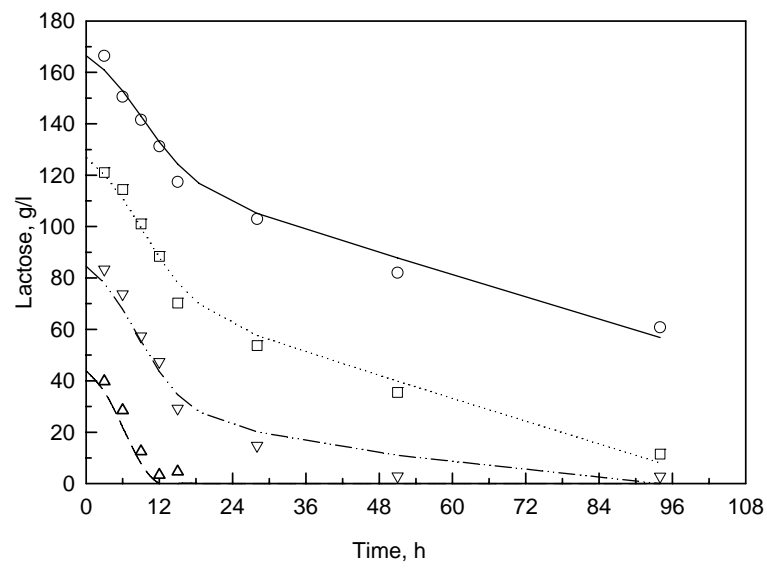

Figure 3: Lactose consumption during $K$. marxianus fermentation of whey supplemented with lactose: $(\triangle) 44$, $(\nabla)$ 85, ( $\square)$ 127, (०) $166 \mathrm{~g} / \mathrm{L}$. Model is shown as lines.

Table 2: Model parameters and determination coefficients calculated for data fit to the model for the different initial lactose concentrations.

\begin{tabular}{|c|c|c|c|c|}
\hline Lactose initial concentration, $\mathrm{g} / \mathrm{L}$ & & 85 & 127 & 166 \\
\hline$Y_{X / S}, \mathrm{~g} / \mathrm{g}$ & 0.093 & 0.087 & 0.093 & 0.086 \\
\hline$m, h^{-1}$ & --- & 0.061 & 0.120 & 0.130 \\
\hline Determination coefficient $\left(\mathrm{R}^{2}\right)$ for lactose consumption fit & 0.997 & 0.986 & 0.997 & 0.998 \\
\hline$Y_{P / S}, \mathrm{~g} / \mathrm{g}$ & 0.51 & 0.51 & 0.45 & 0.45 \\
\hline Determination coefficient $\left(\mathrm{R}^{2}\right)$ for ethanol production fit & 0.98 & 0.98 & 0.997 & 0.993 \\
\hline Efficiency of alcoholic transformation & $94 \%$ & $94 \%$ & $83 \%$ & $83 \%$ \\
\hline
\end{tabular}


After approximately 24 hours the yeast (under assayed conditions) enters stationary phase and because of it the cell growth stops. The consumption of lactose observed is due to the maintenance metabolism and is relatively high as a consequence of the high concentration of yeast and the long time that the yeast was kept culturing (see Figures 1, 2 and 3). The maintenance requirements are mainly energetic requirements. This means that the lactose is consumed for the production of the energy that is used by the cells for their survival. The production of energy using lactose leads to the production of a stoichiometric amount of ethanol (ethanol is the final product of the catabolic route employed by the yeast). The carbon source is not wasted because the objective is the production of ethanol

Optimum fermentation in terms of yield, ethanol productivity and ethanol concentrations is thus considered to be achieved with $127 \mathrm{~g}$ lactose/L, since maximum ethanol concentration (50 g/L) was obtained after 96 hours of fermentation, when all the sugar was practically consumed. In this fermentation an ethanol/sugar yield of 0.45 was obtained.

The $\mathrm{pH}$ of the medium during the fermentations in the Erlenmeyer flasks decreases from the initial value around 6 to approximately 4.0-4.5.

Lastly, the nitrogen source was also monitored. As can be seen in Figure 4, only 20-25\% of total protein is consumed in any case by yeast. Previous papers (Harju et al., 1976; Wasserman, 1960) have shown that yeast cannot assimilate all the nitrogen sources contained in whey. The stop in cell growth observed at high lactose concentrations (see Figure 1) may be due to the depletion of nitrogen sources (there are also other possible nutrient limitations such as vitamins, oligoelements, ...) as previously reported by other authors (Wasserman, 1960). Therefore, a number of experiments with ammonium and yeast extract as nitrogen sources were carried out in order to analyze this hypothesis. These experiments are presented in the next section.

\section{Effect of Nitrogen Sources in K. marxianus Cultivation}

Experiments were carried out in order to study the effect of different nitrogen sources on yeast growth and ethanol production. Two nitrogen sources were tested: ammonium sulphate and yeast extract. Ammonium sulphate releases ammonium, a nitrogen source easily assimilated by yeast cells. Yeast extract is a complex mixture of substances from yeast that represents a source of nitrogen that is also easily assimilated by most microorganisms. It is a complex source of nutrients, containing nitrogen sources, vitamins, oligoelements, salts, growth promoting substances, and many other nutrients. Because it is obtained from dead yeast, it contains all the constituents of yeast cells.

Experiments were carried out to elucidate the effect of each substrate and also mixed effects. $K$. marxianus was cultured in whey supplemented with $100 \mathrm{~g} / \mathrm{L}$ of lactose and $\mathrm{FeCl}_{3}$ as described in Material and Methods - Yeast and Culture Conditions. Ammonium sulphate and yeast extract were added to reach a concentration of $4.7 \mathrm{~g} / \mathrm{L}$ and $6 \mathrm{~g} / \mathrm{L}$, respectively. These concentrations were selected taking into account the work of Kallel et al. (1991). Results obtained are shown in Figure 5.

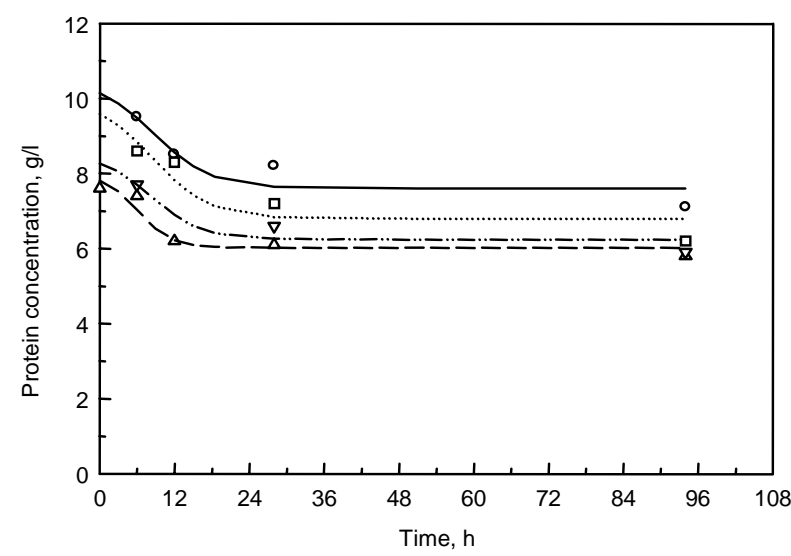

Figure 4: Protein consumption during fermentation of whey supplemented with lactose with K. marxianus: $(\triangle) 44,(\nabla) 85,(\square) 127,(\circ) 166 \mathrm{~g} / \mathrm{L}$. 

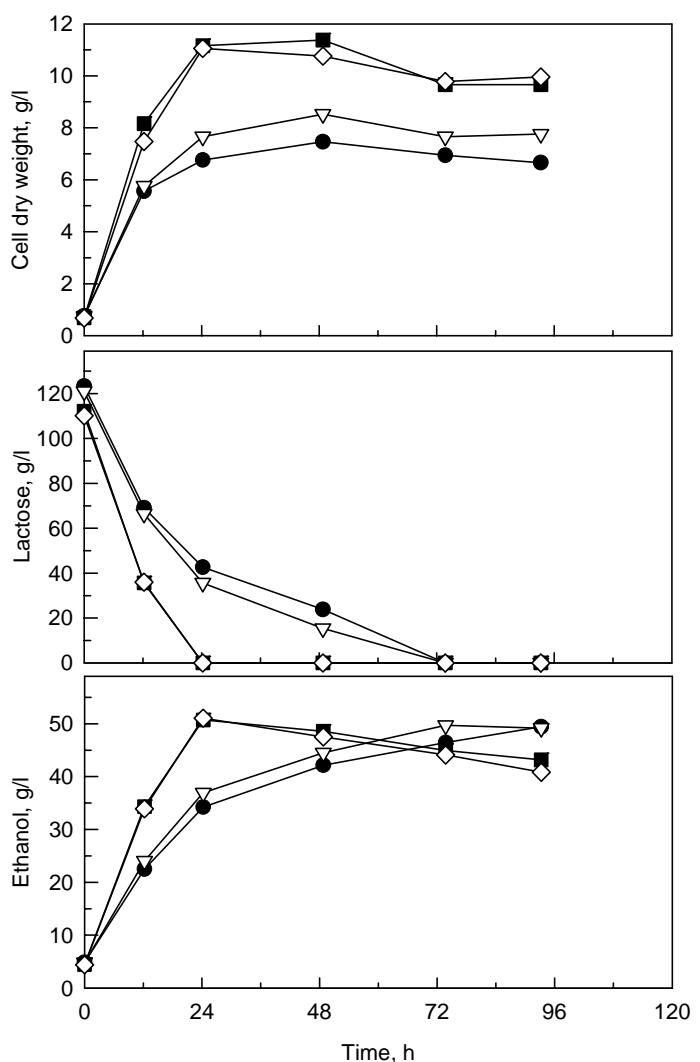

Figure 5: Effect of ammonium sulphate and yeast

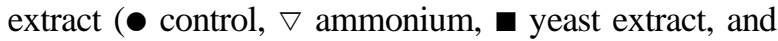
$\diamond$ yeast extract plus ammonium sulphate) on ethanol production, lactose consumption and biomass growth.

Supplementing with ammonium, a nitrogen source easily assimilated by all yeast, did not yield the expected result since yeast growth, specific growth rate and final biomass concentration increased in comparison to the control, but not too much, and hence ethanol production was not as fast as expected. It could be concluded that there must be a limiting substrate other than ammonium for the alcoholic fermentation of whey by K. marxianus.

On the other hand, adding either yeast extract or yeast extract plus ammonium sulphate increased biomass yield from 0.07 to $0.10 \mathrm{~g}$ dry weight per $\mathrm{g}$ lactose (data not shown) and final yeast concentration from nearly 7 to $11 \mathrm{~g} / \mathrm{L}$, measured as dry weight, at 24 hours of growth. Furthermore, in both these cases lactose was depleted at the same time and a final ethanol concentration of $50 \mathrm{~g} / \mathrm{L}$ was obtained. The efficiency of lactose biotransformation into ethanol, calculated as described previously, was $85 \%$ (data not shown). The behaviour in the case of the medium supplied with ammonium was almost the same as the control.

The decrease in the ethanol concentration at the end of the fermentation was probably due to aerobic oxidation of ethanol by yeast. This behaviour is not due to evaporation. A control experiment was done to measure the amount of ethanol lost by evaporation and it was found that the final amount was very similar to the initial concentration. During this stage, the yeast did not grow because it was in the stationary phase. Ethanol (substrate) consumption was used for maintenance of yeast population.

\section{Aeration Promoted Metabolism: Effect of Vitamin Supplementation in Aerobic Growth}

As previously indicated, experiments performed with whey supplemented with yeast extract show high growth rates of yeast. Among the constituents of yeast extract there are several vitamins that may affect cell growth (Andreasen and Stier, 1953). Experiments to explain the effect of yeast extract on yeast growth were carried out, but first the effect of oxygen on the metabolism of K. marxianus was tested.

\section{a) Effect of Oxygen on the Metabolism of $K$. marxianus}

Erlenmeyer flasks of $250 \mathrm{~mL}$ containing $50 \mathrm{~mL}$ of whey supplemented with lactose were used to test the effect of oxygen on the metabolism of $K$. marxianus. In this case, in order to ensure a sufficient oxygen supply, $0.6 \mathrm{~L} / \mathrm{min}$ of pure oxygen was provided to each flask, as described in Material and Methods - Yeast and Culture Conditions.

Results show that the yeast metabolism shifts from fermentation to respiration, as expected. After around 40 hours of cultivation, a concentration of 17 $\mathrm{g} / \mathrm{L}$ of yeast was reached when these aerobic conditions were ensured (Figure 6). Furthermore, no ethanol production was detected. These conditions are suitable for preparation of inocula, for which a high concentration of cells is usually needed.

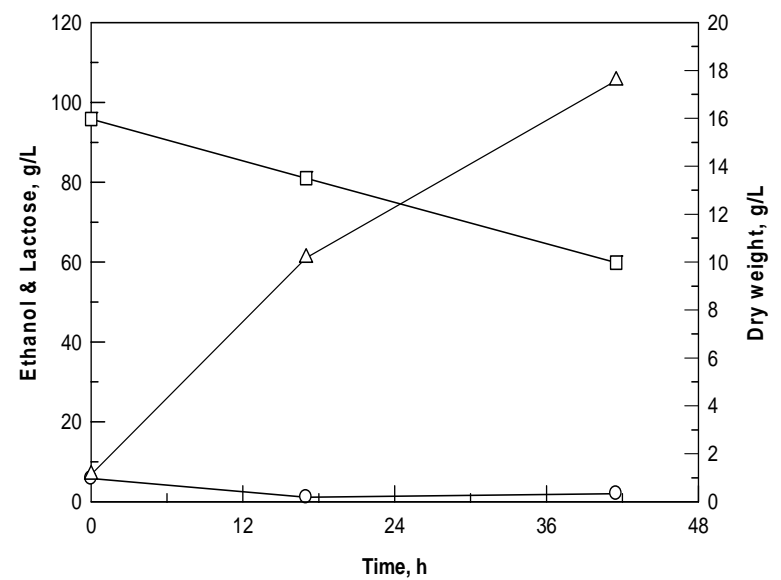

Figure 6: Ethanol production (O), lactose consumption $(\square)$, and biomass growth $(\triangle)$ during aerobic growth of $K$. marxianus in whey supplemented with lactose, at $30^{\circ} \mathrm{C}$ with an aeration of $0.6 \mathrm{~L} \mathrm{O}_{2} / \mathrm{min}$. 


\section{b) Effect of Vitamins on Yeast Growth, Lactose Consumption and Ethanol Production}

Based on previous studies (Harju et al., 1976; Kallel et al., 1991) four vitamins were assayed: nicotinic acid, biotin, pantothenic acid and inositol. Specifically, nicotinic acid has been reported to be a limiting substrate in alcoholic fermentation of whey by K. marxianus (Kallel et al., 1991). Individual and mixed effects were tested, including the effects of four different variables. In order to assure the confidence level of all experiments presented here, an experimental program was designed and performed in triplicate. The differences found in dry weight and ethanol concentration between the triplicates are less than $5 \%$.

In the experiments performed, a medium of whey with food grade lactose supplemented with $\mathrm{Fe}^{3+}$ was used. Each vitamin was added from a stock solution to reach a vitamin concentration in the cultivation medium of $14 \mathrm{mg} / \mathrm{L}$ for nicotinic acid, inositol and pantothenic acid, and $2 \mathrm{mg} / \mathrm{L}$ for biotin. Vitamins were added at a concentration (mg vitamin per gramme of lactose in the medium) in accordance with the work of Kallel (Kallel et al., 1991; KallelMhiri and Miclo, 1995; Kallel-Mhiri and Miclo,
1994). In this case, $0.3 \mathrm{~L} / \mathrm{min}$ of pure oxygen was provided to each flask. Dry weight changes over time and ethanol production are presented in Figure 7. Specific growth rates, final dry weight reached during cultivations, and biomass/ lactose yields are shown in Table 3.

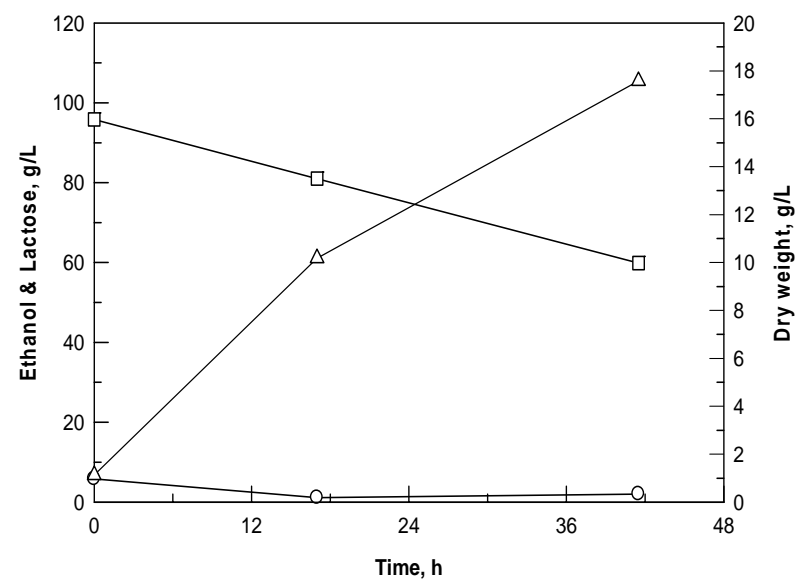

Figure 6: Ethanol production (O), lactose consumption ( $\square$ ), and biomass growth $(\triangle)$ during aerobic growth of $K$. marxianus in whey supplemented with lactose, at $30^{\circ} \mathrm{C}$ with an aeration of $0.6 \mathrm{~L} \mathrm{O} / \mathrm{min}$.
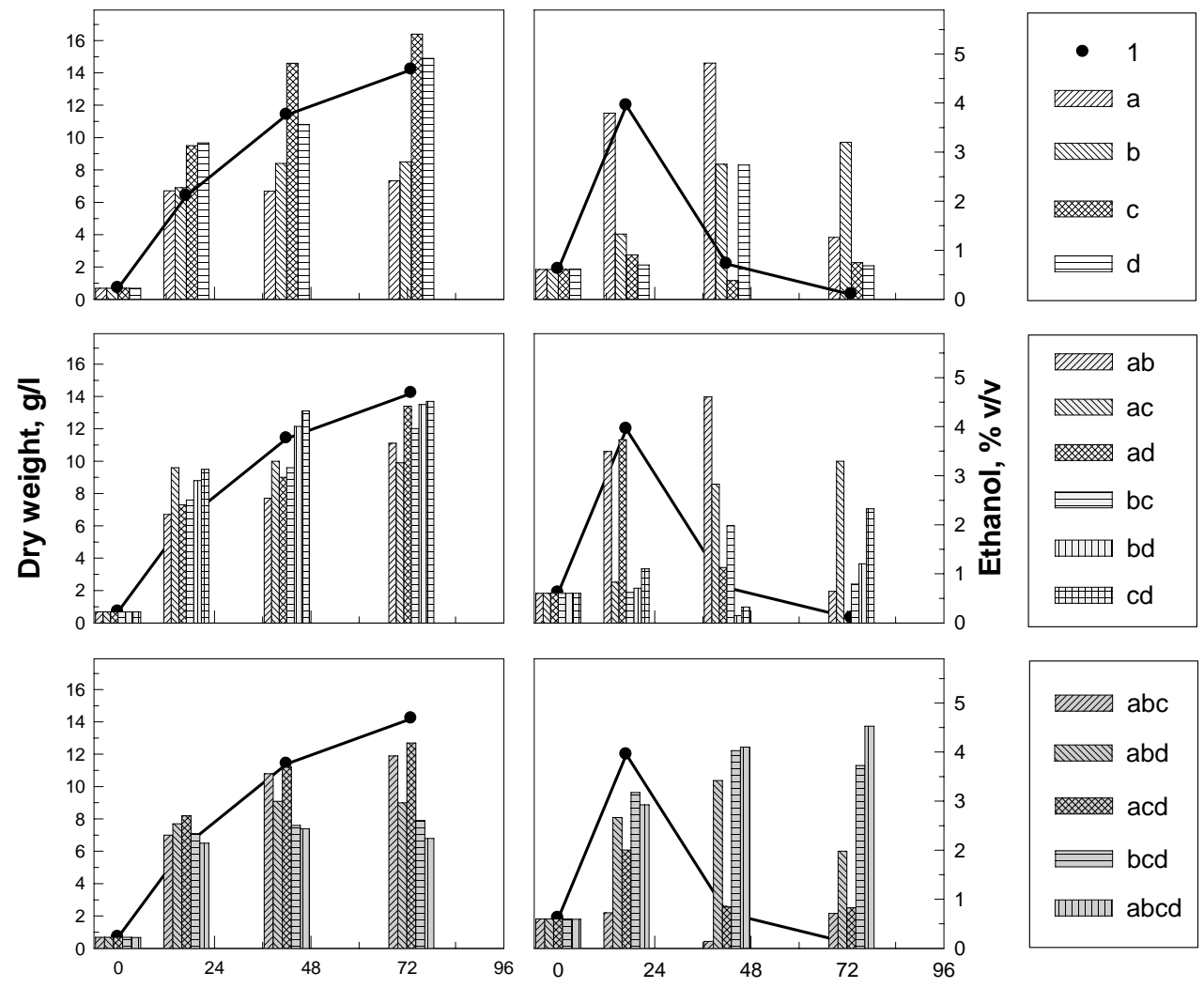

Time, $\mathbf{h}$

Figure 7: Yeast cell growth and ethanol production during K. marxianus fermentation experiments carried out in a medium of lactose supplemented with (A) nicotinic acid, (B) biotin, (C) pantothenic acid and (D) inositol. The letters in the legend represent the different combinations of vitamins added. 
Table 3: Results obtained during a factorial design experiment carried out to analyse the effects of several vitamins on yeast cell growth and lactose consumption. $K$. marxianus was grown aerobically in whey supplemented with food grade lactose and with the following vitamins: (a) nicotinic acid, (b) biotin, (c) pantothenic acid, (d) inositol.

\begin{tabular}{|c|c|c|c|}
\hline Experiment label & $\begin{array}{c}\text { Specific growth rate } \\
\mathbf{( h}^{-\mathbf{1}} \mathbf{n}\end{array}$ & $\begin{array}{c}\text { Final dry weight } \\
\mathbf{( g / \mathbf { L } )}\end{array}$ & $\begin{array}{c}\text { Biomass /lactose yield } \\
\mathbf{( g / g} \mathbf{g})\end{array}$ \\
\hline 1 (control) & 0.09 & 13.8 & 0.11 \\
a (nicotinic acid) & 0.31 & 7.0 & 0.13 \\
b (biotin) & 0.23 & 8.5 & 0.09 \\
c (pantothenic acid) & 0.20 & 15.6 & 0.13 \\
d (inositol) & 0.23 & 12.9 & 0.11 \\
ab & 0.19 & 9.4 & 0.09 \\
ac & 0.35 & 10 & 0.09 \\
ad & 0.26 & 15.2 & 0.10 \\
bc & 0.20 & 10.8 & 0.12 \\
bd & 0.21 & 12.9 & 0.19 \\
abc & 0.22 & 13.4 & 0.10 \\
abd & 0.18 & 11.4 & 0.17 \\
acd & 0.25 & 9.0 & 0.09 \\
bcd & 0.21 & 12.0 & 0.10 \\
abcd & 0.28 & 7.8 & 0.08 \\
\hline
\end{tabular}

Production of ethanol was tested with this lower oxygen flow rate, $0.3 \mathrm{l} / \mathrm{min}$ vs. $0.6 \mathrm{l} / \mathrm{min}$, previously assayed. The ethanol level achieved in the control experiment, $4 \%$ during the first six hours of incubation, is related to the inability to supply enough oxygen to the Erlenmeyer flask at this fast initial step of lactose consumption, as can be shown from an oxygen mass balance. In the calculations was used a $\mathrm{k}_{\mathrm{L}}$ value of $10^{-5} \mathrm{~ms}^{-1}$ estimated using the results of Nikakhtari and Hill (2006). The yeast seemed to display diauxic behaviour since a second step of C-substrate, ethanol, consumption appeared, transforming it effectively into carbon dioxide and water. K. marxianus is considered to be a respiratory yeast and diauxic behaviour (Franzen, 1997) has been described for this type of microorganisms when environmental conditions are not absolutely aerobic but respire-fermentative. It appears that the oxygen supplied to the medium was not enough to convert the sugar in it into carbon dioxide and water and, as a consequence, the sugar was transformed to ethanol. Once sugar has been completely consumed yeast starts to oxidize ethanol. However, when one or more vitamins are present in the medium ethanol, if produced, is not metabolised over these long time periods under the same environmental conditions

Nicotinic acid (14 ppm) shifts yeast from an aerobic metabolism towards fermentation since its presence in the culture medium increased the level of ethanol and the ethanol/lactose yield and decreased biomass concentration and the biomass/lactose yield. Furthermore, the specific cell growth rate was much higher than in the control at $0.31 \mathrm{~h}^{-1}$ vs. $0.09 \mathrm{~h}^{-1}$. These results coincide with those reported by Arnier et al. (1990) and seem to be a consequence of the role that this nicotinic acid plays in the biosynthesis of the cofactors implied in fermentation (Rose and Harrison, 1989). Cells use nicotinic acid, a coenzyme needed in fermentation pathways, in the biosynthesis of NAD. An excess of this vitamin increases fermentation activity as a consequence of the higher activity of alcohol dehydrogenase (Jones et al., 1981).

Adding biotin (2 ppm) decreased final biomass concentrations compared to the levels obtained in the experiment carried out without vitamins, but increased specific growth rates. Biotin also shifted the metabolism towards the production of ethanol but with a slower consumption of lactose (data not shown). Experiments carried out with the addition of inositol to the cultivation broth yielded a final biomass concentration similar to those obtained with the control experiment but with a higher specific growth rate. Pantotenic acid increased biomass production (15\% more than the control), with a slightly higher biomass/lactose yield. Specific growth rate was also higher and similar to that obtained with other vitamins. Addition of two or more vitamins tended to decrease final biomass concentration, with higher specific growth rates, lower lactose consumption (data not shown) and higher ethanol production than in the control.

Seeking to demonstrate the potential effect of nicotinic acid on the aerobic growth of K. marxianus, experiments adding only $2 \mathrm{mg} / \mathrm{L}$ of this vitamin were 
carried out. Magnesium, reported as a limiting factor for yeast growth in whey by Antier et al. (1990) was also added to the medium (1.7 g/L of $\mathrm{MgSO}_{4} .7 \mathrm{H}_{2} 0$ ) in order to check its effect on yeast metabolism. Individual and mixed effects of nicotinic acid and magnesium were tested. Cultivations, including a control, were carried out at $30^{\circ} \mathrm{C}$ and $200 \mathrm{rpm}$, in 250 $\mathrm{mL}$ Erlermeyer flasks filled with $50 \mathrm{~mL}$ of broth into which $0.6 \mathrm{~L} / \mathrm{min}$ of oxygen was introduced. In all cases, metabolism was aerobic and results in terms of cell production and lactose consumption were quite similar to those obtained in the control experiment (data not shown).

Changes in Oxygen, Nitrogen and Phosphorus Sources During Aerobic Growth of $K$. marxianus

To test whether nitrogen in whey was easily assimilated by the strain of $K$. marxianus employed in this work, several experiments were conducted in a $5 \mathrm{~L}$ stirred tank bioreactor with dissolved oxygen control, to ensure growth under aerobic conditions. As the results obtained in the previous section showed that pantothenic acid improved $K$. marxianus growth in aerobic conditions, further experiments were carried out in a modified cultivation broth containing this compound.

During these experiments, carried out in whey supplemented with food grade lactose, oxygen, nitrogen and phosphorous concentrations were analysed in order to detect any deficit in the nutrient composition of the broth. Dissolved oxygen was maintained at $14 \%$ of its saturation value. This value was used on the basis of previous results that showed that under these conditions yeast grow aerobically. The aeration rate was 1 volume of air per volume of medium per minute (v.v.m.). The control system changes the agitation speed in the range 200 and 600 r.p.m. to keep the desired value of dissolved oxygen.

The temperature was kept at $30^{\circ} \mathrm{C}$. The cultivation broth had the following composition: whey powder $78 \mathrm{~g} / \mathrm{L}$, lactose $100 \mathrm{~g} / \mathrm{L}, \mathrm{FeCl}_{3} 24 \mathrm{mg} / \mathrm{l}$, and pantothenic acid $14 \mathrm{mg} / \mathrm{L}$.

An analysis of phosphate, the main source of phosphorous for cell growth, indicates that its concentration was always over $400 \mathrm{mg} / \mathrm{L}$ during the process. As a result, it can be concluded that this is not a limiting substrate for the yeast growth.

The nitrogen source was also monitored during this aerobic cultivation. Total protein nitrogen was analysed by the Lowry method. Peptides were also analysed by the Lowry method, after precipitation of proteins with trichloroacetic acid. Protein concentration was obtained by subtracting peptide concentration from the total nitrogen concentration. Results are shown in Figure 8, where cell dry weight is also represented.

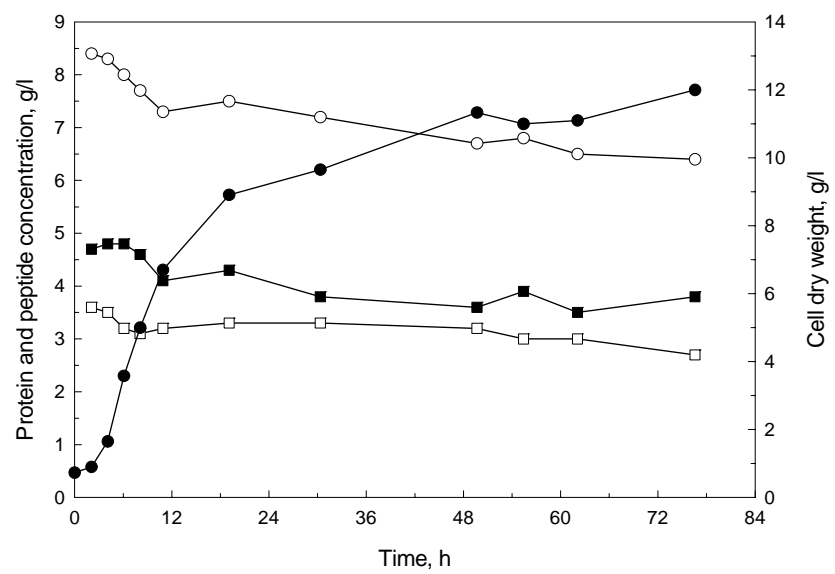

Figure 8: Changes in total protein (०), peptides ( $\square$ ), proteins $(\boldsymbol{\square})$, and cell dry weight $(\bullet)$ during aerobic cell growth of $K$. marxianus in whey supplemented with food lactose.

The yeast growth rate slowed after 12-18 hours, although there were still proteins and peptides in the broth. Wasserman (1960) concluded that $K$. marxianus was only able to assimilate $25 \%$ of the nitrogen of whey. This fraction came from the nitrogen that still remained after precipitation of broth by means of heating in an acid medium. The results obtained here are in accordance with Wasserman's conclusions.

According to Rose and Harrison (1989) proteins of whey cannot be easily assimilated by yeast because $K$. marxianus does not excrete proteases into the cultivation broth. During whey fermentation, the strain of $K$. marxianus employed here only excreted proteases at 10 enzymatic units (EU) (one enzymatic unit was defined as the amount of enzyme that catalyzed the hydrolysis of enough proteins to give a change in absorbance at $520 \mathrm{~nm}$ of 0.1 in $30 \mathrm{~min}$ ).

Peptides also remained in the medium once yeast growth had stopped. This may be due to the fact that the strain of yeast used only grows in the presence of simple nitrogen sources, at least under the experimental conditions employed. Experiments to prove this hypothesis were carried out in the same stirred tank bioreactor described above. The cultivation broth had the following composition: whey powder $78 \mathrm{~g} / \mathrm{L}$, lactose $100 \mathrm{~g} / \mathrm{L}, \mathrm{FeCl}_{3} 20$ $\mathrm{mg} / \mathrm{L}$, pantothenic acid $12 \mathrm{mg} / \mathrm{L}$, and ammonium sulphate $5 \mathrm{~g} / \mathrm{L}$. The oxygen level and temperature were maintained at $14 \%$ saturation value and $30^{\circ} \mathrm{C}$, respectively. The results are presented in Figure 9. 


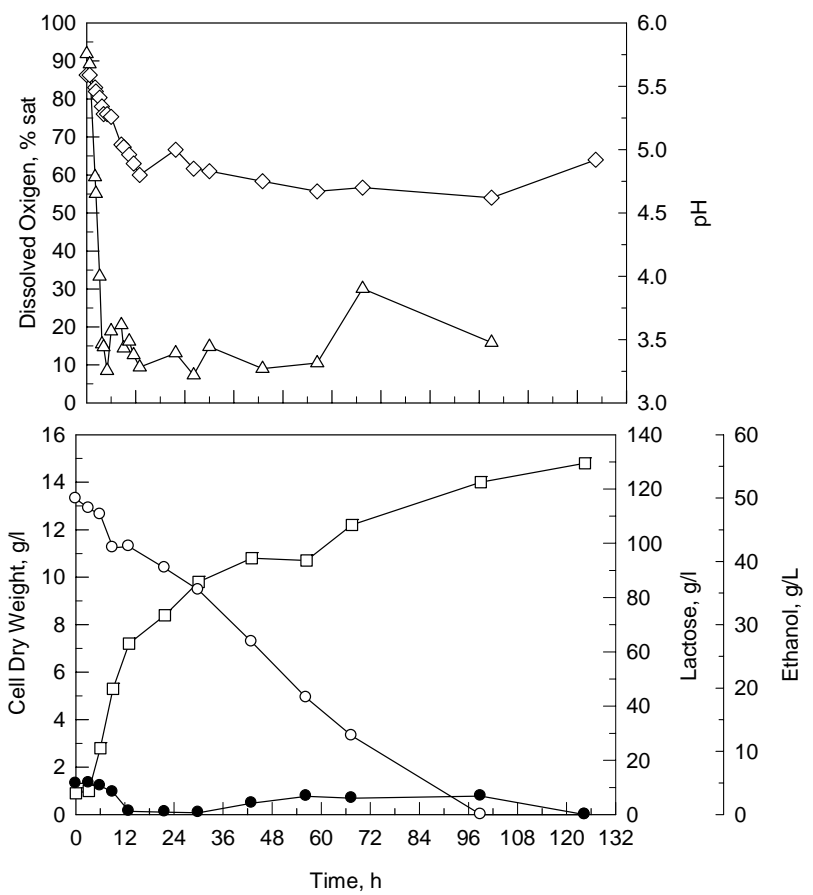

Figure 9: Aerobic growth of $K$. marxianus in lactose-added whey, plus $\mathrm{Mg}^{2+}, \mathrm{Fe}^{2+}$ and pantothenic acid. Fermentation was carried out in a stirred tank reactor at $30^{\circ} \mathrm{C}$, with dissolved oxygen controlled at $14 \%$ saturation value. $(\diamond) \mathrm{pH},(\triangle)$ dissolved oxygen concentration, ( $\square$ ) dry weight, (O) lactose, and (•) ethanol

The $\mathrm{pH}$ of the medium decreased from 5.6 to 4.8 over the first 12 hours of cultivation, and remained approximately constant thereafter. Dissolved oxygen concentration was always above $10 \%$ of the saturation value (13\% as approximate mean medium value). Under these conditions, no ethanol was produced and dry cell weight reached nearly $11 \mathrm{~g} / \mathrm{L}$ after 48 hours of yeast growth, and $15 \mathrm{~g} / \mathrm{L}$ after 5 days. These results are in accordance with those previously obtained by Wasserman (1960). The dry cell weight reached here is clearly lower than the one previously achieved under similar conditions, as presented in Fig 6. In any event, it must be taken into account that those previous experiments were carried out in Erlenmeyer flasks, and the conditions were probably different from this experiment. If this culture was employed as a starter (proportion of 10 volumes of starter per 100 volumes of broth) an initial dry weight of $1.6 \mathrm{~g} / \mathrm{L}$ could be achieved. This figure is in the range recommended by various authors (Rogosa et al., 1947; Veractert and De Mot, 1990).

\section{CONCLUSIONS}

Lactose, oxygen, nitrogen and phosphorus, all of them major components of whey, are essential factors for the growth of $K$. marxianus. But other minor components, such as some vitamins, have also been revealed as compounds decisive to the metabolic pathways finally selected by the yeast. Changes in their concentration provoked changes in the metabolic pathways and, consequently, in the final metabolites achieved.

With low oxygen concentration (no air was added to the medium) adding lactose to whey resulted in an increase in the ethanol produced during fermentation by $K$. marxianus. The optimum concentration of lactose turned out to be $127 \mathrm{~g} / \mathrm{L}$, giving $50 \mathrm{~g}$ ethanol/L and an ethanol/lactose yield of 0.45 . Addition of yeast extract increased the specific growth rate of $K$. marxianus, probably due not only to the presence of a nitrogen source but also to the presence of vitamins in the yeast extract.

Addition of oxygen to the medium previously selected resulted in an increase of final biomass production from 6-7 to $14-15 \mathrm{~g} / \mathrm{L}$. However, the aerobic metabolism in this system seems to be modified when vitamins are added to the medium. Thus, addition of both nicotinic acid and biotin decreased final biomass concentration, increasing the specific growth rate. Furthermore, nicotinic acid shifted the yeast metabolism towards fermentation, since an increase in ethanol production levels was also achieved. Adding two or more vitamins had the intriguing effect of decreasing final biomass concentration, although with a higher specific growth rate, lower lactose consumption and higher ethanol production.

Under the conditions assayed, K. marxianus was only able to assimilate simple nitrogen sources such as aminoacids and ammonium Whey protein could not be assimilated and phosphate was shown not to be a limiting substrate.

\section{ACKNOWLEDGEMENTS}

This work has been funded by a grant from the Ministry of Science and Technology (FPI) of the Spanish Government.

\section{REFERENCES}

Andreasen, A. A. and Stier, T. J. B., Anaerobic Nutrition of Sacharomyces cerevisiae. J. Cell 
Comp. Physiol., 41, 23-36 (1953).

Antier, P., Moulin, G. and Galzy, P., Influence of composition of the culture medium on the behaviour of Kluyveromyces fragilis in chemostat culture, Process Biochem., 25, 9-13 (1990).

Belem, M. A. F. and Lee, B. H., Fed-batch fermentation to produce oligonucleotides from Kluyveromyces marxianus grown on whey, Process Biochem., 34, 501-509 (1999).

Castrillo, J. I. and Ugalde, U. O., Patterns of energy metabolism and growth kinetics of Kluyveromyces marxianus in whey chemostat culture, Appl. Microbiol. Biot., 40, 386-393 (1993).

Dale, M. C., Eagger, A. and Okos, M. R., Osmotic inhibition of free and immobilized Kluyveromyces marxianus anaerobic growth and ethanol productivity in whey permeate concentrate. Process Biochem., 29, 535-544 (1994).

Domingues, L., Lima, N. and Teixeira, J. A., Alcohol production from cheese whey permeate using genetically modified flocculent yeast cells, Biotechnol. Bioeng. 72, 507-514 (2001).

Ferrari, M. D., Loperena, L. and Varela, H., Ethanol production from concentrated whey permeate using a fed-batch culture of Kluyveromyces fragilis, Biotechnol. Lett., 16, 205-210 (1994).

Franzén, C. J., Analysis and control of continuous microaerobic ethanol production by yeast, $\mathrm{PhD}$ Thesis, Chapter 2, Department of Chemical Reaction Engineering, Chalmers University of Technology, Göteborg, Sweden (1997).

Guimaraes, W. V., Dudey, G. L. and Ingram L. O., Fermentation of sweet whey by ethanologenic Escherichia coli, Biotechnol. Bioeng., 40, 41-45 (1992).

Hahn-Hägerdal, B., Enzymes co-immobilized with microorganisms for the microbial conversion of non-metabolizable substrates, Acta Chem. Scand., B 34, 611-613 (1980).

Harju, M., Heikonen, M. and Kreula, M., Nutrient supplementation of Swiss cheese whey for the production of feed yeast, Milchwissenschaft, 31, 530-534 (1976).

Jones R. P., Pamment, N. and Greefield, P. F., Alcohol fermentation by yeast- the effect of environmental and other variables, Process Biochem., 16, 42-49 (1981).

Kallel, H., Garridosanchez L, Engasser J. M., and Miclo, A., Optimization of a continuous culture of Kluyveromyces marxianus on whey permeate effects of minerals and vitamins on the yeast growth and metabolism. Microbiologie -Aliments -Nutrition, 9, 309-317 (1991).
Kallel-Mhiri, H. and Miclo, A., Kinetics of lactose transport in Kluyveromyces fragilis grown in a chemostat on diluted whey permeate, J. Ind. Microbiol., 15, 45-48 (1995).

Kallel-Mhiri, H., Valance, C., Engasser, J. M. and Miclo, A., Yeast continuous mixed cultures on whey permeate and hydrolysed starch, Process Biochem., 29, 381-386 (1994).

Miller, G. L., Use of dinitrosalicylic acid reagent for determination of reducing sugar, Anal Chem., 31, 426-428 (1959).

Nikakhtari, H, Hill G. A., Closure Effects on Oxygen Transfer and Aerobic Growth in Shake Flasks. Biotech \& Bioeng., 95, 16-21 (2006).

Parrondo, J., Garcia, L. A. and Diaz, M., Production of an alcoholic beverage by fermentation of whey permeate with Kluyveromyces fragilis I. primary metabolism, J. I. Brewing, 106, 367-375 (2000).

Parrondo, J., Garcia L. A. and Diaz, M., Production of an alcoholic beverage by fermentation of whey permeate with Kluyveromyces fragilis II: aroma composition, J. I. Brewing, 106, 377-382 (2000).

Peña, C., Trujillo-Roldan, M. A. and Galindo, E., Influence of dissolved oxygen tension and agitation speed on alginate production and its molecular weight in cultures of Azotobacter vinelandii, Enzyme Microb. Tech., 27, 390-398 (2000).

Rodney, P. J. and Greenfield, P. F., A review of yeast ionic nutrition. Part I: growth and fermentation requirements. Process Biochem., 4, 48-60 (1984).

Rogosa, M., Browne, H, N. and Whittier, E. O., Ethyl alcohol from whey. J Dairy Sci. 30, 263269 (1947).

Rose, A. H. and Harrison, J. S., The Yeast, Volume 3, Academic Press Limited, London (1989).

Verachtert, H. and De Mot, R., Yeast, Biotechnology and biocatalysis, Marcel Dekker Inc, New York (1990).

Vienne, P. and von Stockar, U., Metabolic, physiological and kinetic aspects of the alcoholic fermentation of whey permeate by Kluyveromyces marxianus NRRL 665 and Kluyveromyces lactis NCYC 571, Enzyme Microb. Technol., 7, 287-294 (1985).

Walker, G. M. and O’Neill, J. D., Morphological and metabolic changes in the yeast Kluyveromyces marxianus var. marxianus NRRLy2415 during fermentation of lactose. J. Chem. Technol. Biot., 49, 75-89 (1990).

Wasserman, A. E., Whey utilization. IV. Availability of whey nitrogen for the growth of Saccharomyces marxianus. J. Dairy Sci., 43, 1231-1234 (1960). 